Check for updates

Cite this: RSC Adv., 2019, 9, 17273

Received 26th April 2019 Accepted 20th May 2019

DOI: 10.1039/c9ra03116b

rsc.li/rsc-advances

\section{Mesoporous semiconductors combined with up- conversion nanoparticles for enhanced photodynamic therapy under near infrared light $\uparrow$}

\author{
Fan Yang, ${ }^{a}$ Jun Liu, ${ }^{a}$ Xue Jiang, ${ }^{a}$ Weiwei Wu, (D) ${ }^{b} Z^{2}$ enni Wang, ${ }^{b}$ Qi Zeng ${ }^{a}$ \\ and Ruichan Lv (D)*a
}

Photodynamic therapy (PDT) is a promising and effective method for tumor therapy that relies on the reactive oxygen species (ROS) produced by photosensitizers at specific wavelengths to inhibit tumor cells. Inorganic semiconductive materials are potential photosensitizers that can excellently absorb ultraviolet light to produce ROS to kill cancer cells. However, this strategy is still limited in terms of practical applications due to the weak penetration of ultraviolet light through biological tissue, as well as the hypoxic tumor microenvironment, largely decreasing ROS generation. In this research, novel PDT agents made with mesoporous lanthanide-semiconductor composites are developed to obtain a remarkable amount of generated ROS under near-infrared (NIR) laser irradiation. Due to the larger size (about $120 \mathrm{~nm}$ ) of the up-conversion material (UCM) used as the substrate, coated with different amounts of semiconductors with mesoporous morphologies, this platform could emit higher blue emission under a $980 \mathrm{~nm}$ laser. Meanwhile, both of the semiconductors $\left(\mathrm{SnO}_{2}\right.$ and $\left.\mathrm{TiO}_{2}\right)$ used have wide absorbance bands in the ultraviolet region, and the ultraviolet fluorescence emitted from the UCM core under NIR laser excitation can be used as the energy donor. Electron transfer processes in $\mathrm{SnO}_{2}$ and $\mathrm{TiO}_{2}$ are generated via the above platforms and produce ROS through photochemical action. Furthermore, the coated semiconductors are mesoporous with larger surface areas (about $302 \mathrm{~m}^{2} \mathrm{~g}^{-1}$ ) and various channels; this is beneficial to obtain enough oxygen to generate more ROS under a hypoxic environment. The PDT efficiency of a typical $\mathrm{NaYF}_{4} \mathrm{CSnO}_{2}$ sample is studied using a DPBF detector, in vitro MTT assays, and in vivo tumor inhibition experiments, revealing that this lanthanide-semiconductor platform could be potentially used as a PDT agent under NIR excitation.

\section{Introduction}

In recent years, compared with traditional radiotherapy and chemotherapy, photodynamic therapy (PDT) has attracted many researchers in the field of cancer treatment because of its few side effects, obvious efficacy, strong targeting, relatively low cost, and non-invasive mode of treatment. ${ }^{1-3}$ The main principle of PDT is to activate photosensitizers under radiation of a suitable wavelength to induce photodynamic effects leading to the production of reactive oxygen species

\footnotetext{
${ }^{a}$ Engineering Research Center of Molecular and Neuro Imaging, Ministry of Education, School of Life Science and Technology, Xidian University, Xi'an, Shaanxi 710071, China.E-mail: rclv@xidian.edu.cn

${ }^{b}$ School of Advanced Materials and Nanotechnology, Xidian University, Xi'an, Shaanxi 710071, China

$\dagger$ Electronic supplementary information (ESI) available: SEM images and TEM images of the $\mathrm{NaYF}_{4}: \mathrm{Yb}, \mathrm{Tm}$ precursor; the particle size distribution of $\mathrm{NaYF}_{4}: \mathrm{Yb}, \mathrm{Tm}$; the average shell thicknesses of three NYF@Sn samples; the average shell thicknesses of four NYF@Ti samples; $\mathrm{N}_{2}$ adsorption/desorption isotherms and the pore size distribution of the NYF@Ti2 composite; and a schematic diagram of NIR-induced ROS. See DOI: 10.1039/c9ra03116b
}

(ROS), which cause necrosis and apoptosis in diseased cells. ${ }^{4}$ Compared with traditional organic photosensitizers (e.g., Ce6 and $\mathrm{ZnPc}$ ), inorganic semiconductors (e.g., $\mathrm{TiO}_{2}, \mathrm{SnO}_{2}$, $\mathrm{MnO}_{2}$, etc.) with better biocompatibility can be stably maintained in the body longer with no obvious toxicity. ${ }^{5-8}$ Inorganic semiconductors can be utilized as photocatalysts and photosensitizer agents simultaneously. ${ }^{\mathbf{9 1 0}}$ When a semiconductor is excited by energy from photons, electrons from the valence band can be excited to the conduction band, creating electron-hole pairs. Then, if they do not recombine, the electrons and holes can reduce or oxidize substances in the electrolyte solution. For example, in aqueous solution, holes oxidize water molecules to generate hydroxyl radicals $(\cdot \mathrm{OH})$, and electrons reduce oxygen $\left(\mathrm{O}_{2}\right)$ to produce superoxide anions $\left(\mathrm{O}_{2}{ }^{-}\right)$or hydrogen peroxide $\left(\mathrm{H}_{2} \mathrm{O}_{2}\right) . \mathrm{O}_{2}{ }^{-}$is a single electron reduction product of oxygen, $\mathrm{H}_{2} \mathrm{O}_{2}$ is a twoelectron reduction product of oxygen, and $\cdot \mathrm{OH}$ is a threeelectron reduction product of oxygen; they are all ROS. ${ }^{\mathbf{1 0 , 1 1}}$ However, it is still difficult to extend current clinical photodynamic therapy options to the NIR excitation range due to the limitations of existing photosensitizers; also, biological 
tissue absorbs visible ultraviolet light more strongly, which causes the excitation light to penetrate the tissue to a depth of only 1-2 mm. These factors easily lead to the failure of PDT toward cancer cells. ${ }^{\mathbf{1 2 , 1 3}}$

Studies of the optical window of biological tissue have shown that incident light in the near-infrared (NIR) range (700-1000 nm) has the greatest penetration into the tissue and it can penetrate the tissue by several centimeters. ${ }^{\mathbf{1 4 - 2 0}}$ It would be very promising to transfer the excitation light wavelength during the PDT process into the NIR region. To overcome the drawbacks of the weak tissue penetration of ultraviolet light in the PDT field, combining the photosensitizer with an upconversion material has been proposed. ${ }^{21-27}$ Lanthanide-doped upconversion materials (UCMs) can absorb long-wavelength incident light and convert it into short-wavelength emission, such as converting near-infrared light into ultraviolet-visible light; for this purpose, the surface modification of upconversion materials has been widely used in biomedicine. ${ }^{28-36}$ Moreover, if a semiconductor is combined with an UCM, the excitation laser wavelength can be adjusted to the near-infrared region, and the obtained upconversion visible emission can be used for real-time image-guided diagnosis. ${ }^{37-41}$

Most recently, there have been reports on the application of $\mathrm{TiO}_{2}$ combined upconversion nanocomposites to PDT. ${ }^{42,43}$ Also, in our previous work, we have proved that ROS could be generated due to energy transfer from the upconversion blue emission of a lanthanide-based compound to a $\mathrm{TiO}_{2}$-based photocatalyst that was responsive to blue emission. ${ }^{44}$ However, up to now, there are several problems to be resolved relating to the structures of the energy donor UCM and energy acceptor photocatalyst: (1) commonly used upconversion substrates are too small (less than $50 \mathrm{~nm}$ ), resulting in unstable combination and small amounts of attached $\mathrm{TiO}_{2}$; (2) the structures of the photocatalysts used are always simple, and the surface areas of the bulk morphologies are not high enough to generate a sufficient amount of ROS; and (3) when inorganic PDT agents are used in hypoxic tumor cells, the PDT efficiency is further limited because of a lack of oxygen. ${ }^{45-50}$ Due to these three main reasons, PDT efficiency is not satisfactory under simple excitation pump power.

In this work, we used a slightly larger up-conversion material ( $\sim 120 \mathrm{~nm}$ diameter) as the substrate, coated with different amounts of semiconductors with mesoporous morphologies. Due to the larger surface area with various channels, $\mathrm{NaYF}_{4} @ \mathrm{SnO}_{2}$ and $\mathrm{NaYF}_{4} @ \mathrm{TiO}_{2}$ have good photodynamic efficiency. Both of the semiconductors $\left(\mathrm{SnO}_{2}\right.$ and $\left.\mathrm{TiO}_{2}\right)$ have wide absorbance bands in the ultraviolet region, and the ultraviolet fluorescence emitted from the $\mathrm{NaYF}_{4}$ core under NIR laser excitation can be used as the energy donor. Electron transfer processes in $\mathrm{SnO}_{2}$ and $\mathrm{TiO}_{2}$ are generated in the above platforms and produce ROS, undergoing photochemical action. The PDT efficiency of a typical $\mathrm{NaYF}_{4} @$ $\mathrm{SnO}_{2}$ sample is studied using DPBF, in vitro MTT assays, and in vivo tumor inhibition experiments.

\section{Experimental section}

\section{Materials}

All chemical reagents were used as received without further purification. Yttrium oxide $\left(\mathrm{Y}_{2} \mathrm{O}_{3}, 99.99 \%\right)$, ytterbium oxide
$\left(\mathrm{Yb}_{2} \mathrm{O}_{3}, 99.9 \%\right)$, thulium oxide $\left(\mathrm{Tm}_{2} \mathrm{O}_{3}, 99.99 \%\right)$, ethylenediaminetetraacetic acid disodium salt dihydrate (EDTA), sodium fluoride (NaF), poly(acrylic acid) (PAA), sodium tetrafluoroborate $\left(\mathrm{K}_{2} \mathrm{SnO}_{3}\right)$, urea $\left(\mathrm{CON}_{2} \mathrm{H}_{4}\right)$, diethylenetriamine (DETA), and titanium isopropoxide, were purchased from the Shanghai Aladdin Bio-Chem Technology Co., Ltd., Shanghai, China. Isopropanol was obtained from the China National Pharmaceutical Group Corporation.

\section{Synthesis of $\mathrm{NaYF}_{4}: \mathrm{Yb}^{3+}, \mathrm{Tm}^{3+}$ upconversion nanoparticles (denoted as NYF)}

The synthesis of the precursor was carried out according to a previous work. ${ }^{51}$ Typically, $0.8 \mathrm{mmol}$ of EDTA was dissolved in $15 \mathrm{~mL}$ of deionized water, and $4 \mathrm{~mL}$ of $0.2 \mathrm{M} \mathrm{RE}\left(\mathrm{NO}_{3}\right)_{3}$ mixture solution ( $\mathrm{Y}: \mathrm{Yb}: \mathrm{Tm}=70: 30: 0.5)$ was added to the above solution under stirring at room temperature for $1 \mathrm{~h}$. Then $12 \mathrm{~mL}$ of aqueous $\mathrm{NaF}(0.8 \mathrm{M})$ was added to the above solution and it was stirred for another hour. Then the mixed solution was transferred into a $50 \mathrm{~mL}$ Teflon-lined autoclave and this was heated at $180{ }^{\circ} \mathrm{C}$ for $2 \mathrm{~h}$. The autoclave was cooled to room temperature naturally, and the obtained precipitates were collected via centrifugation, washed with deionized water and ethanol three times, and then dried in air at $60^{\circ} \mathrm{C}$ for $12 \mathrm{~h}$.

\section{Synthesis of $\mathrm{NaYF}_{4}: \mathrm{Yb}^{3+}, \mathrm{Tm}^{3+} @ \mathrm{SnO}_{2}$ core/shell nanoparticles (denoted as NYF@Sn)}

This process of coating with $\mathrm{SnO}_{2}$ of different thicknesses was carried out with slight changes to the published literature. ${ }^{52}$ Typically, $40 \mathrm{mg}$ of NYF UCNPs and $0.08 \mathrm{~g}$ of PAA were put into $25 \mathrm{~mL}$ of ultrapure water and, after ultrasonication for $20 \mathrm{~min}$, the mixed solution was stirred at $50{ }^{\circ} \mathrm{C}$ for 6 hours. Then, the above solution was centrifuged and the obtained precipitate was put into ultrapure water (UPW)/ethanol solution $\left(\mathrm{v}_{\mathrm{UPW}^{-}}\right.$ $\left.: \mathrm{v}_{\text {ethanol }}=15.625: 9.625 \mathrm{~mL}\right)$. A certain amount of urea $(40 \mathrm{mg})$ and $\mathrm{K}_{2} \mathrm{SnO}_{3}(10 \mathrm{mg})$ was added and the mixture was stirred for $10 \mathrm{~min}$. Finally, the mixture was transferred into a $50 \mathrm{~mL}$ Teflon-lined autoclave and kept at $170{ }^{\circ} \mathrm{C}$ for $12 \mathrm{~h}$. The obtained NYF@Sn was centrifuged and washed with deionized water and ethanol three times before drying at $60{ }^{\circ} \mathrm{C}$ for $720 \mathrm{~min}$. The thickness of $\mathrm{SnO}_{2}$ could be adjusted by adding different amounts of $\mathrm{K}_{2} \mathrm{SnO}_{3}-5 \mathrm{mg}, 10 \mathrm{mg}$, and $20 \mathrm{mg}$ - and the corresponding core/shell nanoparticles are denoted as NYF@Sn1, NYF@Sn2, and NYF@Sn3, respectively.

\section{Synthesis of $\mathrm{NaYF}_{4}: \mathrm{Yb}^{3+}, \mathrm{Tm}^{3+} @ \mathrm{TiO}_{2}$ core/shell nanoparticles (denoted as NYF@Ti)}

The process of coating with $\mathrm{TiO}_{2}$ with different morphologies was carried out with slight changes to the published literature. ${ }^{53}$ Typically, $25 \mathrm{mg}$ of NYF UCNPs was dissolved in $21 \mathrm{~mL}$ of isopropanol via sonication, followed by the addition of $0.02 \mathrm{~mL}$ of DETA. After the solution was stirred for $10 \mathrm{~min}, 1 \mathrm{~mL}$ of titanium isopropoxide was added and stirring was continued for $10 \mathrm{~min}$. Then, the above solution was transferred into a $50 \mathrm{~mL}$ Teflon-lined autoclave and maintained at $200{ }^{\circ} \mathrm{C}$ for $24 \mathrm{~h}$. After the autoclave cooled to room temperature naturally, the products were separated via centrifugation, washed with ethanol 
three times, and then dried at $60{ }^{\circ} \mathrm{C}$ for $12 \mathrm{~h}$. Finally, the obtained NYF@Ti was calcined in a muffle furnace at $350{ }^{\circ} \mathrm{C}$ for $2 \mathrm{~h}$ at a heating rate of $1^{\circ} \mathrm{C} \mathrm{min}^{-1}$ to make highly crystalline phase anatase $\mathrm{TiO}_{2}$. The thickness of $\mathrm{TiO}_{2}$ could be adjusted by adding different amounts of titanium isopropoxide $-0.1 \mathrm{~mL}$, $0.2 \mathrm{~mL}$, and $0.6 \mathrm{~mL}$ - and the corresponding core/shell nanoparticles are denoted as NYF@Ti1, NYF@Ti2, and NYF@Ti3, respectively.

\section{Singlet oxygen detection via DPBF}

A DPBF probe was used to detect the production of reactive oxygen species. In a dark environment, $2 \mathrm{~mL}$ of NYF@Sn/ NYF@Ti aqueous solution $\left(0.32 \mathrm{mg} \mathrm{mL} \mathrm{mL}^{-1}\right)$ was prepared in a $10 \mathrm{~mm}$ cuvette, and then $36 \mu \mathrm{L}$ of DPBF ethanol solution $(1 \mathrm{M})$ was added. Then, absorbance spectra of the solution were sequentially detected using a UV spectrophotometer after irradiation with a $980 \mathrm{~nm}$ NIR laser for different time periods (0 $\mathrm{min}, 2 \mathrm{~min}, 4 \mathrm{~min}, 6 \mathrm{~min}$, and $8 \mathrm{~min}$ ).

\section{In vitro cytotoxicity of NYF@Sn and NYF@Ti}

MTT assays were carried out to detect the cytotoxicity of NYF@Sn and NYF@Ti towards cells. SGC 7901 cells were incubated overnight in a 96-well plate at 5000 per well to obtain a monolayer, then different concentrations of samples $(0,31.25$, $62.5,125,250$ and $500 \mu \mathrm{g} \mathrm{mL} \mathrm{m}^{-1}$ ) were added before incubation at $37{ }^{\circ} \mathrm{C}$ for 24 hours under a $5 \% \mathrm{CO}_{2}$ atmosphere. Thereafter, each well was washed several times with PBS, and then $200 \mu \mathrm{L}$ of medium and $20 \mu \mathrm{L}$ of MTT solution $\left(5 \mathrm{mg} \mathrm{mL}^{-1}\right)$ were added. After the 96-well plate was further incubated for 4 hours at $37{ }^{\circ} \mathrm{C}$, the solution was discarded and $100 \mu \mathrm{L}$ of DMSO was added. Finally, the plate was shaken for $20 \mathrm{~min}$, and then the absorbance of the cells was recorded at a wavelength of $490 \mathrm{~nm}$ using a microplate reader.

\section{In vitro anticancer efficiency using MTT assays}

After SGC 7901 cells were cultured in 96-well plates for 12 hours to form a monolayer, NYF@Sn2 and NYF@Ti2 at a certain concentration $\left(500 \mu \mathrm{g} \mathrm{mL}^{-1}\right)$ were added and incubated with the cells for 4 hours. Then each well was washed three times using PBS, discarding the mixture, followed by the addition of $100 \mu \mathrm{L}$ of fresh medium to every well and irradiation with a $980 \mathrm{~nm}$ laser $\left(1 \mathrm{~W} \mathrm{~cm}^{-2}\right)$ for different time periods $(1 \mathrm{~min}$, $2 \mathrm{~min}$ and $5 \mathrm{~min}$ ). Simultaneously, untreated cells were used as controls for cells treated with laser irradiation. Afterwards, the therapeutic effects of the semiconductor photodynamic materials were confirmed via detecting the cell viability using MTT assays. The treated and untreated cells were stained with Calcein $\mathrm{AM}$ and PI for 15 minutes at $37{ }^{\circ} \mathrm{C}$ and $5 \% \mathrm{CO}_{2}$, and background fluorescence interference was removed via washing several times using PBS; then fluorescence images were obtained via a Leica DMI 4000 B instrument.

\section{In vivo anticancer efficiency}

All experiments were conducted in accordance with internationally accepted laboratory animal use and care guidelines and the protocol was approved by the School of Pharmacy Ethics Committee. Mice were acclimatized for one week before the study, and the mice were provided with water and food pellets until the end of the experimental period. The animal study procedures were approved and followed by the Xi'an Jiaotong University Animal Care and Use Committee. 4T1 cells dissolved in the medium were injected subcutaneously into the right hind limbs of BALB/c mice (4-5 weeks; $18-22 \mathrm{~g}$ ). When tumors grew to $\sim 30 \mathrm{~mm}^{3}$, a mouse tumor model was established and the in vivo experiments could be started. The mice were divided into two groups, the control group and the treatment group, with three mice in each group. No measures were taken for the control group. For the treatment group, NYF@Sn2 dissolved in PBS was injected into the mice tumors, and the tumors were irradiated with a $980 \mathrm{~nm}$ NIR laser for ten minutes. Laser treatment was conducted every two days and for a total of four times. Body weight and tumor size data from the two groups of mice were recorded every two days during the eight-day treatment cycle.

\section{Results and discussion}

\section{Structure and morphology}

The synthesis of the cubic-phase $\mathrm{NaYF}_{4}: \mathrm{Yb}^{3+}, \mathrm{Tm}^{3+}$ nanoparticles is facile and precipitation is uniform. During the synthesis process, the solubility of NYF is not very good and it will precipitate in the aqueous solution for a long time. Therefore, PAA is used to modify the surface functionality of NYF, leading to better NYF hydrophilicity, which is advantageous for coating the semiconductors on the surface of the precursor. SEM images and TEM images are shown in Fig. S1; $\dagger$ the synthesized NYF is relatively uniform in size (about $120 \mathrm{~nm}$ ) and has good dispersibility (Fig. S2†).

Two facile hydrothermal methods are used for the synthesis of NYF coated with $\mathrm{SnO}_{2}$ and $\mathrm{TiO}_{2}$ shells. Both the formed NYF@Sn and NYF@Ti preserve their original spherical structure; porous $\mathrm{SnO}_{2}$ and $\mathrm{TiO}_{2}$ shells are coated on NYF with adjustable morphologies. For NYF@Sn, we can control the thickness of the $\mathrm{SnO}_{2}$ shell by changing the amount of $\mathrm{K}_{2} \mathrm{SnO}_{3}$ added during the reaction. In Fig. 1A-C, NYF@Sn samples with $\mathrm{SnO}_{2}$ shells of increasing thickness (from $5 \mathrm{~nm}$ to $15 \mathrm{~nm}$ ) are presented, corresponding to the addition of $5 \mathrm{mg}, 10 \mathrm{mg}$, and $20 \mathrm{mg}$ of $\mathrm{K}_{2} \mathrm{SnO}_{3}$, respectively (Fig. S3 $\dagger$ ). For NYF@Ti (Fig. 2), we synthesized three samples of NYF@Ti with different thicknesses (from $8 \mathrm{~nm}$ to $103 \mathrm{~nm}$ ) by changing the amount of isopropyl titanate added $(0.1 \mathrm{~mL}, 0.2 \mathrm{~mL}, 0.6 \mathrm{~mL}$, and $1 \mathrm{~mL})$ (Fig. S4 $\dagger$ ). NYF@Ti1 with a thinner $\mathrm{TiO}_{2}$ shell has a shell thickness of $\sim 8 \mathrm{~nm}$, and the coating is uniform. When coated with a thicker $\mathrm{TiO}_{2}$ shell, NYF@Ti3 remains uniform with a thickness of $\sim 103 \mathrm{~nm}$. Further typical morphology analysis is presented in Fig. 3. As shown, NYF@Sn2 with a thickness of $10 \mathrm{~nm}$ is mono-dispersed (Fig. 3A), and the porous $\mathrm{SnO}_{2}$ is clearly visible (Fig. 3B). Element mapping imaging and energy dispersive spectroscopy (EDS) data demonstrate the presence of $\mathrm{Na}, \mathrm{Y}, \mathrm{Yb}, \mathrm{Tm}, \mathrm{F}, \mathrm{O}$ and Sn elements, as shown in Fig. 3C, confirming that $\mathrm{SnO}_{2}$ is successfully coated on the NYF core and the elements are dispersed uniformly. The surfaces of the core- 


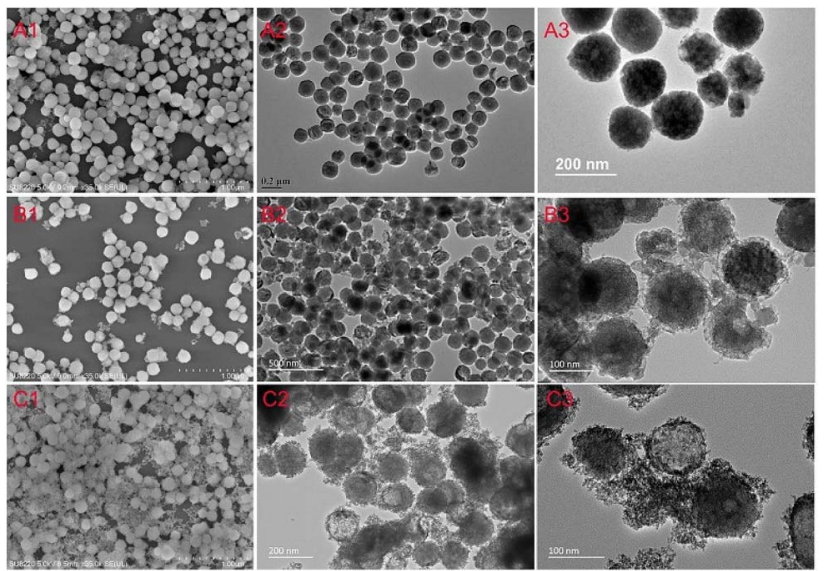

Fig. 1 SEM images and TEM images of NYFaSn synthesized from different amounts of $\mathrm{K}_{2} \mathrm{SnO}_{3}$ : (A1-A3) $5 \mathrm{mg}$; (B1-B3) $10 \mathrm{mg}$; and (C1C3) $20 \mathrm{mg}$. Here, the amount of added NYF is $25 \mathrm{mg}$.

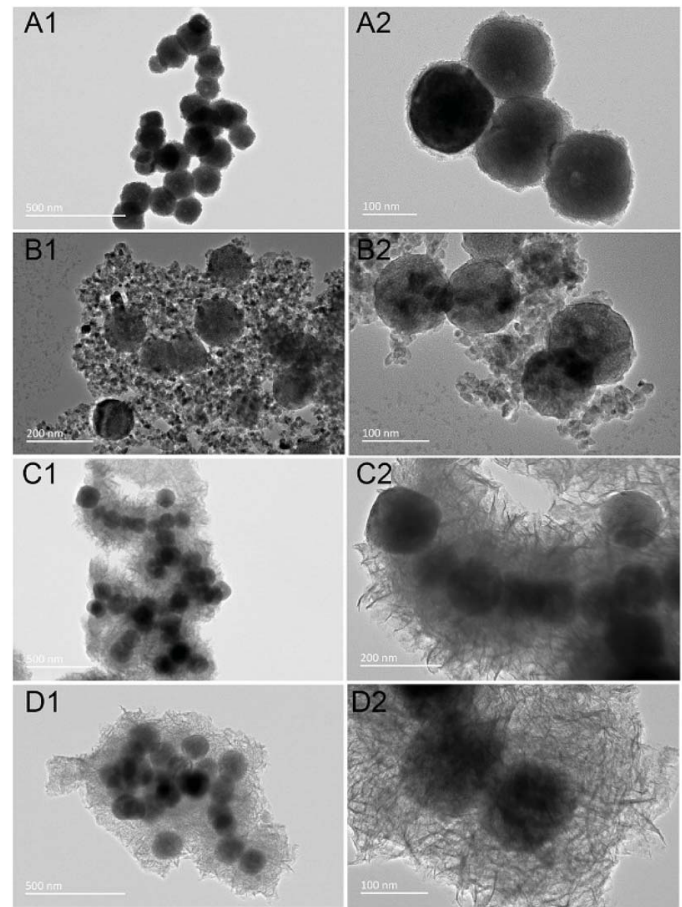

Fig. 2 TEM images of NYF(Ti synthesized with different amounts of isopropyl titanate: (A1 and A2) $100 \mu \mathrm{L}$; (B1 and B2) $200 \mu \mathrm{L}$; (C1 and C2) $600 \mu \mathrm{L} ;$ and (D1 and D2) $1000 \mu \mathrm{L}$. Here, the amount of added NYF is $25 \mathrm{mg}$.

shell nanoparticles become rough due to the porous shell, which increases the specific surface area and is more favorable for absorbing incident light for upconversion; the shell can also achieve better photocatalysis.

Fig. 4A shows XRD patterns of the as-synthesized precursor, and NYF@Sn2 and NYF@Ti2 samples. As shown, the peaks of the precursor correspond well with JCPDS 06-0342. After coating with $\mathrm{TiO}_{2}$ or $\mathrm{SnO}_{2}$ separately, the typical peaks of $\mathrm{TiO}_{2}$ or $\mathrm{SnO}_{2}$ occur correspondingly, further indicating the successful
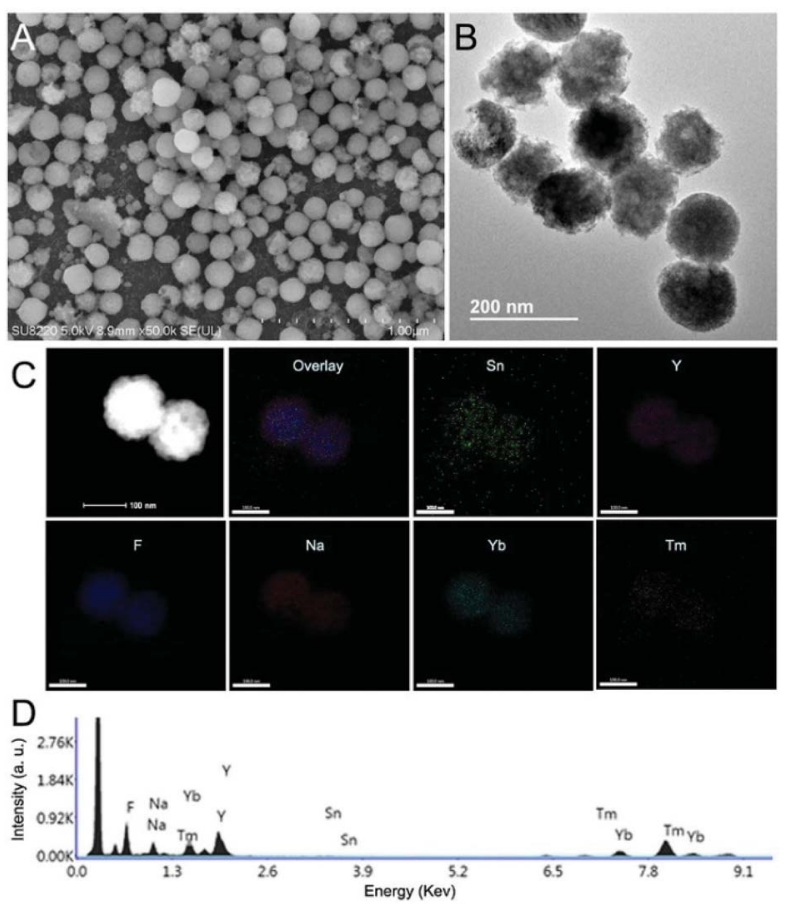

Fig. 3 (A) An SEM image, (B) a TEM image, (C) element mapping data, and (D) EDS results from NYF@Sn2.

combination of the semiconductors. The $\mathrm{N}_{2}$ adsorption/ desorption isotherm of a typical NYF@Sn2 composite was further detected and is shown in Fig. 4B. It is clear that the assynthesized NYF@Sn2 shows a H1 hysteresis loop, indicating typical mesopores and channels. The BET surface area, pore volume, and average pore width are calculated to be $84 \mathrm{~m}^{2} \mathrm{~g}^{-1}$, $0.23 \mathrm{~cm}^{3} \mathrm{~g}^{-1}$, and $17 \mathrm{~nm}$, respectively (Fig. 4C), while the detected BET surface area, pore volume, and average pore width of NYF@Ti2 are $185 \mathrm{~m}^{2} \mathrm{~g}^{-1}, 0.24 \mathrm{~cm}^{3} \mathrm{~g}^{-1}$ and $19 \mathrm{~nm}$, respectively (Fig. S5 $\dagger$ ). These large BET surface areas and pore sizes are beneficial for absorbing oxygen in water and tissue, which is helpful for improving the PDT efficiency.

\section{Optical properties and ROS detection}

Upconversion luminescence spectra of NYF, NYF@Sn2 and NYF@Ti2 under laser irradiation at $980 \mathrm{~nm}$ are shown in Fig. 5A and C. The NYF UCNPs show typical $\mathrm{Tm}^{3+}$ photoluminescence emission characteristics. In the ultraviolet region, two emission peaks appear at $347 \mathrm{~nm}$ and $362 \mathrm{~nm}$, induced by the radioactive transitions of ${ }^{1} \mathrm{I}_{6} \rightarrow{ }^{3} \mathrm{~F}_{4}$ and ${ }^{1} \mathrm{D}_{2} \rightarrow{ }^{3} \mathrm{H}_{6}$. Two blue emission peaks are located at $452 \mathrm{~nm}$ and $475 \mathrm{~nm}$, derived from the electronic transitions of ${ }^{1} \mathrm{D}_{2} \rightarrow{ }^{3} \mathrm{~F}_{4}$ and ${ }^{1} \mathrm{G}_{4} \rightarrow{ }^{3} \mathrm{H}_{6}$, respectively. ${ }^{54} \mathrm{~A}$ red emission peak at $646 \mathrm{~nm}$ is derived from the ${ }^{1} \mathrm{G}_{4}$ $\rightarrow{ }^{3} \mathrm{~F}_{4}$ transitions of $\mathrm{Tm}^{3+}$ ions. After coating with the $\mathrm{SnO}_{2}$ shell (or $\mathrm{TiO}_{2}$ shell), almost all of the peaks are weakened, while the peak at $646 \mathrm{~nm}$ is unchanged. This phenomenon has two main causes: firstly, the $\mathrm{SnO}_{2}$ shell (or $\mathrm{TiO}_{2}$ shell) attenuated a portion of the NIR light, resulting in a decrease in the intensity of the excitation light reaching the NYF core; secondly, the $\mathrm{Tm}^{3+}$ ion transitions became weaker because $\mathrm{SnO}_{2}\left(\right.$ or $\left.\mathrm{TiO}_{2}\right)$ absorbed 

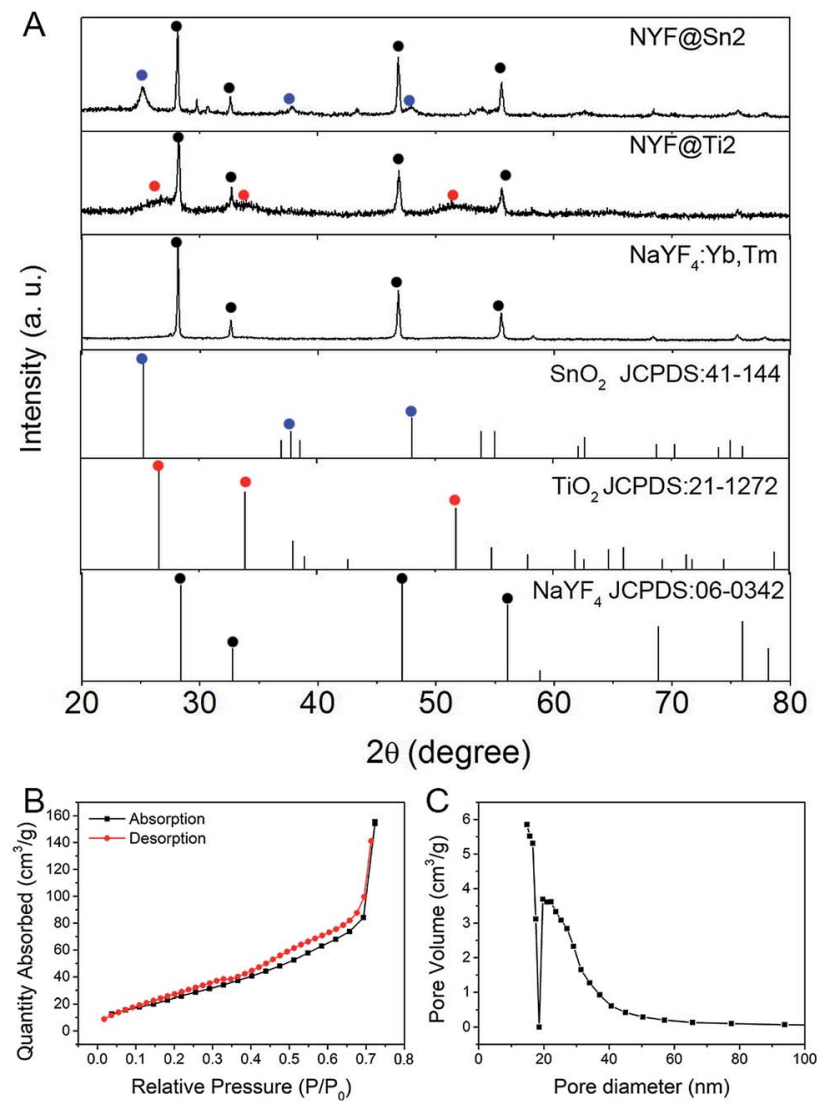

Fig. 4 (A) XRD patterns of as-synthesized samples. (B) The $\mathrm{N}_{2}$ adsorption/desorption isotherm and (C) pore size distribution of the NYFaSn2 composite.
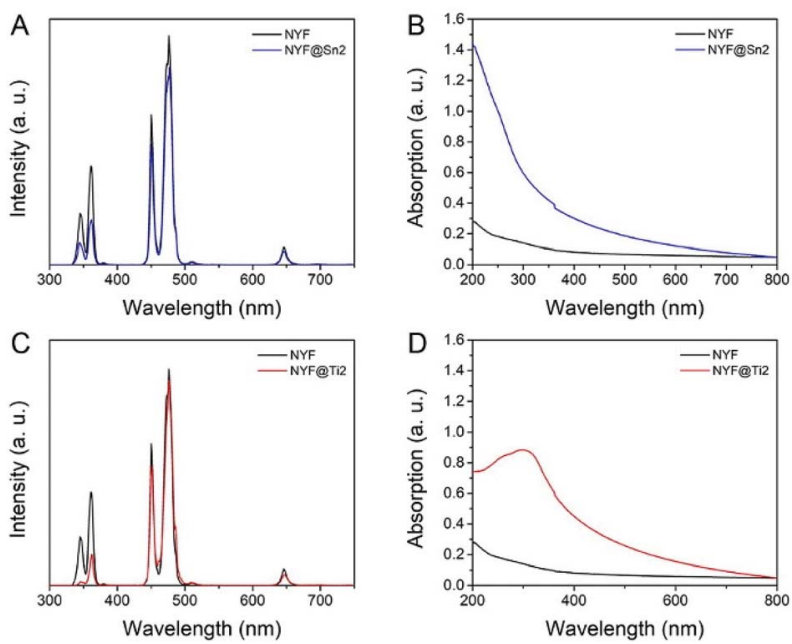

Fig. 5 Upconversion luminescence spectra of the NYF precursor and (A) NYF@Sn2 or (C) NYFaTi2 under $980 \mathrm{~nm}$ excitation. UV-vis absorbance spectra of NYF solution and (B) NYFaSn2 solution or (D) NYFaTi2 solution.

a part of the ultraviolet light emitted by $\mathrm{Tm}^{3+}$. Therefore, the two peaks in the ultraviolet region decreased more. UV-vis absorbance spectra of NYF, NYF@Sn2 and NYF@Ti2 are measured and compared in Fig. 5B and D. NYF has almost no absorbance in the range of $200 \mathrm{~nm}$ to $800 \mathrm{~nm}$. However, NYF@Sn2 has a strong and sharp absorbance edge from $400 \mathrm{~nm}$ to $200 \mathrm{~nm}$, which corresponds to the absorbance characteristics of $\mathrm{SnO}_{2}$, and this edge covers the ${ }^{1} \mathrm{I}_{6} \rightarrow{ }^{3} \mathrm{~F}_{4}$ and ${ }^{1} \mathrm{D}_{2} \rightarrow{ }^{3} \mathrm{H}_{6}$ emission peaks of NYF, confirming the theory that $\mathrm{SnO}_{2}$ absorbed the emitted light of NYF. Similarly, NYF@Ti2 has a broad absorbance peak in the ultraviolet region, which also overlaps with the emission peaks of $\mathrm{Tm}^{3+}$ ions at $374 \mathrm{~nm}$ and $362 \mathrm{~nm}$ and corresponds to the intrinsic absorbance of $\mathrm{TiO}_{2}$.

The chemical probe 1,3-diphenylisobenzofuran (DPBF) is used to detect the active oxygen produced by the photodynamic action of NYF@Sn2 and NYF@Ti2 under excitation from a $980 \mathrm{~nm}$ NIR laser. ROS can react irreversibly with DPBF, resulting in a decrease in the characteristic absorbance peak of DPBF at $420 \mathrm{~nm}$. Under NIR irradiation, the UV/blue light emitted from the NYF core is absorbed by the $\mathrm{SnO}_{2}\left(\right.$ or $\left.\mathrm{TiO}_{2}\right)$ shell. Then, electrons in the semiconductor valence band are excited to the conduction band and holes are generated in the valence band. A schematic diagram of this NIR-induced PDT process can be seen in Scheme S1 $\uparrow$. These electron-hole pairs are transferred to the surface of $\mathrm{SnO}_{2}$ and react with substances in the solvent, and the ROS generated in this process reduce the characteristic peak of DPBF. It can be seen in Fig. 6 that the characteristic absorbance peak at $420 \mathrm{~nm}$ of DPBF solution mixed with NYF@Sn or NYF@Ti decreases significantly after different periods of NIR laser irradiation. As the NIR irradiation time increases, the characteristic peak drops more. After $8 \mathrm{~min}$ of NIR irradiation, NYF@Sn2 produces the most ROS, reducing the absorbance peak of DPBF by $86 \%$ (Fig. 6C), while the singlet oxygen generated in the greatest amount by NYF@Ti2 decreases the characteristic peak of DPBF by $49 \%$ (Fig. $6 \mathrm{E}$ ).
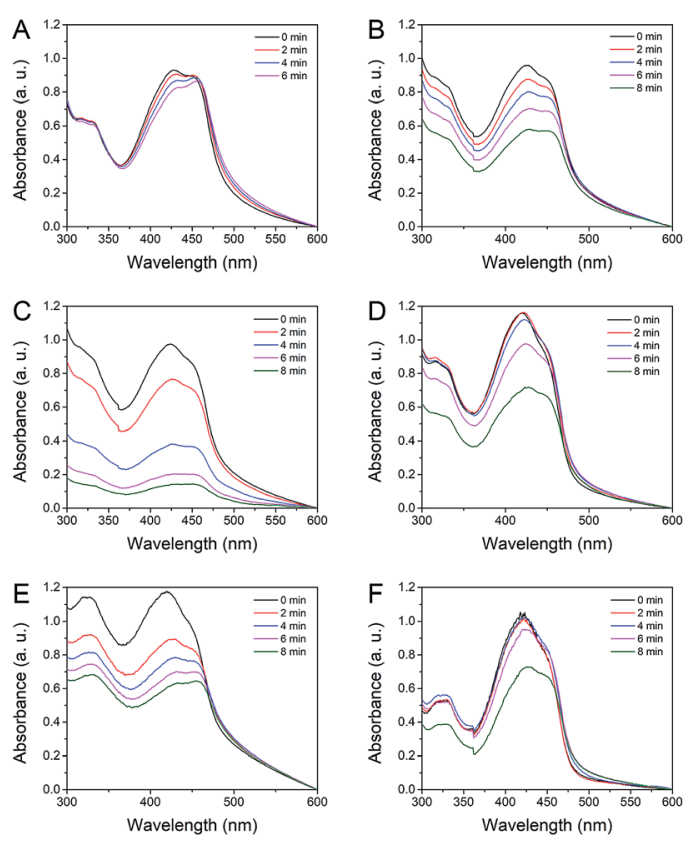

Fig. 6 Absorbance spectra of DPBF solution treated with $(A)$ the NYF precursor, (B), NYF@Sn1, (C) NYF@Sn2, (D) NYF@Sn3, (E) NYF@Ti2, and (F) NYF(ATi3 at different irradiation time points. 


\section{In vitro and in vivo photodynamic therapy effects}

Based on the morphology and PDT efficiency, we chose NYF@Sn2 and NYF@Ti2 as the final PDT agents. Before the prepared PDT agents were subjected to biological applications, their biocompatibilities were firstly assessed. The cytotoxicity of NYF@Sn2 and NYF@Ti2 towards cells was determined using the MTT method. Fig. 7A illustrates cell viability data after incubation with NYF@Sn and NYF@Ti (different concentrations) at $37{ }^{\circ} \mathrm{C}$. It can be seen that the cell survival rate is maintained at $85 \%$ overall after incubation with NYF@Sn, and the cell survival rate after incubation with NYF@Ti is 90\% on average. This shows that both samples have good biocompatibility and can be applied to photodynamic therapy.

In vitro anticancer efficiency assays under $980 \mathrm{~nm}$ NIR irradiation were further carried out. Compared with the control group, with an increase in the $980 \mathrm{~nm}$ laser irradiation time $(1,2$ and $5 \mathrm{~min}$ ), the cell viability is significantly reduced as a result of the photodynamic effects of the samples. When cells are incubated with NYF@Sn2 under $980 \mathrm{~nm}$ laser irradiation, the cell viability decreases to $80 \%$ after $6 \mathrm{~min}$, while under the influence of NYF@Ti2, the cell viability decreases more before eventually decreasing to $70 \%$ (Fig. 7B). This indicates that the ROS produced by the photodynamic effects of NYF@Sn2 and NYF@Ti2 under $980 \mathrm{~nm}$ laser irradiation inhibit cell growth. Furthermore, microscopy images of cells incubated with NYF@Sn2 without and with $980 \mathrm{~nm}$ laser irradiation for $10 \mathrm{~min}$ are shown in Fig. 7C and D.

To test the in vivo photodynamic therapy effects of NYF@Sn, we established an animal model of 4T1 tumor cells. The tumorbearing mice were divided into two groups: a blank group was used as a control and the treatment group was treated with NYF@Sn under a NIR laser. Mouse body weight (Fig. 8A) and tumor size (Fig. 8B) changes were recorded every two days during the treatment cycle. Eight days later, we found that the tumors of the control mice grew to $120 \mathrm{~mm}^{3}$, while the tumors of the treated mice were reduced to $10 \mathrm{~mm}^{3}$. This shows that

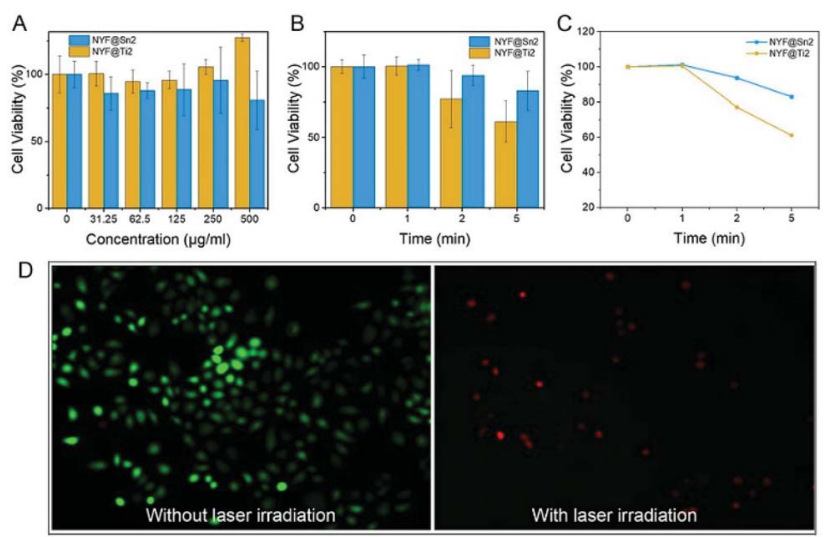

Fig. 7 The viability of cells incubated with NYFaSn2 and NYF@Ti2 at different concentrations $(A)$ without laser irradiation and $(B)$ following different irradiation exposure times, obtained using MTT assays. AM/PI stained images of cells (C) before and (D) after PDT treatment under $980 \mathrm{~nm}$ laser irradiation.
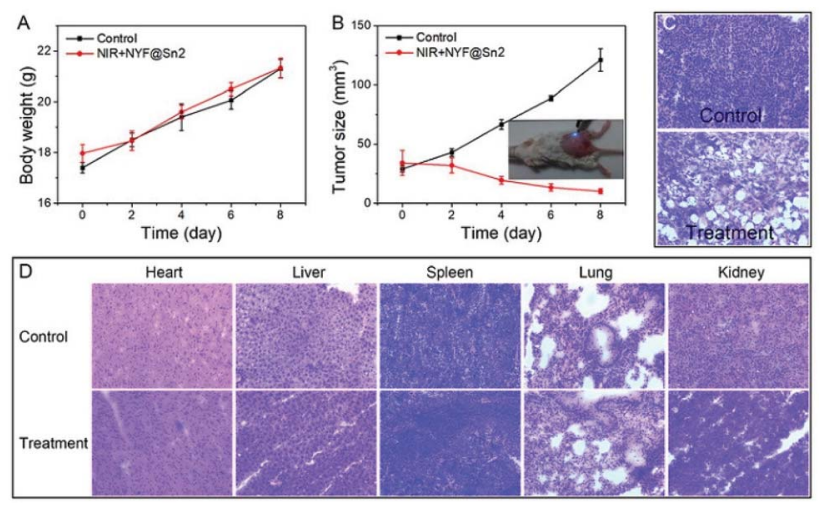

Fig. 8 (A) Body weight and (B) tumor size changes in mice from control and treatment groups over 8 days. H\&E stained images of (C) a tumor and (D) heart, liver, spleen, lung, and kidney samples from the control group and NYF@Sn treatment group.

photodynamic therapy with NYF@Sn worked. Fig. 8C shows H\&E stained tissue sections of tumor and major organ samples from the blank and treated mice group. As can be seen from the tumor sections, many necrotic and apoptotic cells appear in the tumor tissue after treatment compared with the control group. In the organs of heart, liver, spleen, lung and kidney, normal cells are found in both mouse groups and no abnormal necrosis is detected (Fig. 8D).

\section{Conclusions}

In summary, we synthesized a series of lanthanidesemiconductor PDT agents in the form of $\mathrm{NaYF}_{4}$ :$\mathrm{Yb}$,Tm@SnO ${ }_{2}$ and $\mathrm{NaYF}_{4}: \mathrm{Yb}, \mathrm{Tm} @ \mathrm{TiO}_{2}$, in which $\mathrm{SnO}_{2}$ and $\mathrm{TiO}_{2}$ act as photosensitizers. For the two core-shell composites, both the porous $\mathrm{SnO}_{2}$ and $\mathrm{TiO}_{2}$ shells are relatively uniformly coated on the surface of NYF. NYF@Sn and NYF@Ti have good photodynamic characteristics under $980 \mathrm{~nm}$ laser irradiation; the produced ROS significantly weakened the characteristic absorbance peak of DPBF, the survival rates of cells incubated with the photosensitizers were reduced after NIR irradiation, and the growth of living tumors was inhibited after periodic light therapy. This combination of upconversion materials and semiconducting photosensitizers, using near-infrared light with its deeper penetration of biological tissue as the excitation light and semiconductors with higher energy conversion efficiencies as photosensitizers, can be better applied to future photodynamic therapy research.

\section{Conflicts of interest}

There are no conflicts to declare.

\section{Acknowledgements}

This work was supported by the Natural Science Foundation of China (NSFC 81801744), the National Key R\&D Program of 
China Grant (No. 2017YFA0205202), and the Fundamental Research Funds for the Central Universities.

\section{References}

1 Z. Zhou, J. Song, L. Nie and X. Chen, Chem. Soc. Rev., 2016, 45, 6597-6626.

2 A. Bansal, F. Yang, T. Xi, Y. Zhang and J. S. Ho, Proc. Natl. Acad. Sci. U. S. A., 2018, 115, 1469-1474.

3 D. Dolmans, D. Fukumura and R. K. Jain, Nat. Rev. Cancer, 2003, 3, 380-387.

4 G. Zheng, J. Chen, K. Stefflova, M. Jarvi, H. Li and B. C. Wilson, Proc. Natl. Acad. Sci. U. S. A., 2007, 104, 89898994.

5 M. Feng, R. Lv, L. Xiao, B. Hu, S. Zhu, F. He, P. Yang and J. Tian, Inorg. Chem., 2018, 57, 14594-14602.

6 R. Lv, P. Yang, B. Hu, J. Xu, W. Shang and J. Tian, ACS Nano, 2017, 11, 1064-1072.

7 N. M. Idris, M. K. Gnanasammandhan, J. Zhang, P. C. Ho, R. Mahendran and Y. Zhang, Nat. Med., 2012, 18, 1580-1586. 8 L.-S. Lin, J. Song, L. Song, K. Ke, Y. Liu, Z. Zhou, Z. Shen, J. Li, Z. Yang, W. Tang, G. Niu, H.-H. Yang and X. Chen, Angew. Chem., Int. Ed., 2018, 57, 4902-4906.

9 C. Zhang, K. Zhao, W. Bu, D. Ni, Y. Liu, J. Feng and J. Shi, Angew. Chem., Int. Ed., 2015, 54, 1770-1774.

10 E. Ju, K. Dong, Z. Chen, Z. Liu, C. Liu, Y. Huang, Z. Wang, F. Pu, J. Ren and X. Qu, Angew. Chem., Int. Ed., 2016, 55, 11467-11471.

11 C. Seidl, J. Ungelenk, E. Zittel, T. Bergfeldt, J. P. Sleeman, U. Schepers and C. Feldmann, ACS Nano, 2016, 10, 31493157.

12 J. Hu, Y. a. Tang, A. H. Elmenoufy, H. Xu, Z. Cheng and X. Yang, Small, 2015, 11, 5860-5887.

13 I. S. Turan, D. Yildiz, A. Turksoy, G. Gunaydin and E. U. Akkaya, Angew. Chem., Int. Ed., 2016, 55, 2875-2878.

14 J. Xu, A. Gulzar, P. Yang, H. Bi, D. Yang, S. Gai, F. He, J. Lin, B. Xing and D. Jin, Coord. Chem. Rev., 2019, 381, 104-134.

15 X. Ai, L. Lyu, Y. Zhang, Y. Tang, J. Mu, F. Liu, Y. Zhou, Z. Zuo, G. Liu and B. Xing, Angew. Chem., Int. Ed., 2017, 56, 30313035.

16 M.-H. Chan and R.-S. Liu, Nanoscale, 2017, 9, 18153-18168.

17 X. Wang, S. S. Huang, W. D. W. Heston, H. Guo, B.-C. Wang and J. P. Basilion, Mol. Cancer Ther., 2014, 13, 2595-2606.

18 X. Yue, Q. Zhang and Z. Dai, Adv. Drug Delivery Rev., 2017, 115, 155-170.

19 W. Zheng, P. Huang, Z. Gong, D. Tu, J. Xu, Q. Zou, R. Li, W. You, J.-C. G. Bunzli and X. Chen, Nat. Commun., 2018, 9, 3462 .

20 Q. Gong, R. Zou, J. Xing, L. Xiang, R. Zhang and A. Wu, Adv. Sci., 2018, 5, 1700664.

21 J. Zhou, Q. Liu, W. Feng, Y. Sun and F. Li, Chem. Rev., 2015, 115, 395-465.

22 K. Liu, X. Liu, Q. Zeng, Y. Zhang, L. Tu, T. Liu, X. Kong, Y. Wang, F. Cao, S. A. G. Lambrechts, M. C. G. Aalders and H. Zhang, ACS Nano, 2012, 6, 4054-4062.

23 C. Chen, F. Wang, S. Wen, Q. P. Su, M. C. L. Wu, Y. Liu, B. Wang, D. Li, X. Shan, M. Kianinia, I. Aharonovich,
M. Toth, S. P. Jackson, P. Xi and D. Jin, Nat. Commun., 2018, 9, 3290.

24 J. Shen, G. Chen, T. Y. Ohulchanskyy, S. J. Kesseli, S. Buchholz, Z. Li, P. N. Prasad and G. Han, Small, 2013, 9, 3213-3217.

25 M. Haase and H. Schaefer, Angew. Chem., Int. Ed., 2011, 50, 5808-5829.

26 X. Liu, C.-H. Yan and J. A. Capobianco, Chem. Soc. Rev., 2015, 44, 1299-1301.

27 R. Lv, M. Feng and W. J. Parak, Nanomaterials, 2018, 8, 989. 28 G. Tian, X. Zheng, X. Zhang, W. Yin, J. Yu, D. Wang, Z. Zhang, X. Yang, Z. Gu and Y. Zhao, Biomaterials, 2015, 40, 107-116.

29 J. V. Garcia, J. Yang, D. Shen, C. Yao, X. Li, R. Wang, G. D. Stucky, D. Zhao, P. C. Ford and F. Zhang, Small, 2012, 8, 3800-3805.

30 Y. Wang, S. Song, J. Liu, D. Liu and H. Zhang, Angew. Chem., Int. Ed., 2015, 54, 536-540.

31 L.-D. Sun, Y.-F. Wang and C.-H. Yan, Acc. Chem. Res., 2014, 47, 1001-1009.

32 A. Escudero, A. I. Becerro, C. Carrillo-Carrion, N. O. Nunez, M. V. Zyuzin, M. Laguna, D. Gonzalez-Mancebo, M. Ocana and W. J. Parak, Nanophotonics, 2017, 6, 881-921.

33 H. Wen, H. Zhu, X. Chen, T. F. Hung, B. Wang, G. Zhu, S. F. Yu and F. Wang, Angew. Chem., Int. Ed. Engl., 2013, 52, 13419-13423.

34 W. Fan, W. Bu and J. Shi, Adv. Mater., 2016, 28, 3987-4011. 35 J. Wang, R. Deng, M. A. MacDonald, B. Chen, J. Yuan, F. Wang, D. Chi, T. S. A. Hor, P. Zhang, G. Liu, Y. Han and X. Liu, Nat. Mater., 2014, 13, 157-162.

36 H. H. Gorris and O. S. Wolfbeis, Angew. Chem., Int. Ed., 2013, 52, 3584-3600.

37 R. Bardhan, S. Lal, A. Joshi and N. J. Halas, Acc. Chem. Res., 2011, 44, 936-946.

38 D. Wang, D. Wang, A. Kuzmin, A. Pliss, W. Shao, J. Xia, J. Qu and P. N. Prasad, Adv. Opt. Mater., 2018, 6, 1701142.

39 Y. Yang, Q. Shao, R. Deng, C. Wang, X. Teng, K. Cheng, Z. Cheng, L. Huang, Z. Liu, X. Liu and B. Xing, Angew. Chem., Int. Ed., 2012, 51, 3125-3129.

40 S. Zeng, Z. Yi, W. Lu, C. Qian, H. Wang, L. Rao, T. Zeng, H. Liu, H. Liu, B. Fei and J. Hao, Adv. Funct. Mater., 2014, 24, 4051-4059.

41 R. Lv, M. Feng, L. Xiao, J. A. Damasco, J. Tian and P. N. Prasad, ACS Appl. Bio Mater., 2018, 1, 1505-1511.

42 Y. Liu, Y. Liu, W. Bu, C. Cheng, C. Zuo, Q. Xiao, Y. Sun, D. Ni, C. Zhang, J. Liu and J. Shi, Angew. Chem., Int. Ed., 2015, 54, 8105-8109.

43 S. S. Lucky, N. M. Idris, Z. Li, K. Huang, K. C. Soo and Y. Zhang, ACS Nano, 2015, 9, 191-205.

44 R. Lv, C. Zhong, R. Li, P. Yang, F. He, S. Gai, Z. Hou, G. Yang and J. Lin, Chem. Mater., 2015, 27, 1751-1763.

45 R. Song, M. Zhang, Y. Liu, Z. Cui, H. Zhang, Z. Tang, X. Chen, H. Wu, Z. Yao, M. He and W. Bu, Biomaterials, 2018, 175, 123-133.

46 Z. Yin, D. Chen, J. Zou, J. Shao, H. Tang, H. Xu, W. Si and X. Dong, ChemistrySelect, 2018, 3, 4366-4373. 
47 G. Lan, K. Ni, Z. Xu, S. S. Veroneau, Y. Song and W. Lin, J. Am. Chem. Soc., 2018, 140, 5670-5673.

48 L. Du, S. Liao, H. A. Khatib, J. F. Stoddart and J. I. Zink, J. Am. Chem. Soc., 2009, 131, 15136-15142.

49 Y. Liu, Y. Liu, W. Bu, Q. Xiao, Y. Sun, K. Zhao, W. Fan, J. Liu and J. Shi, Biomaterials, 2015, 49, 1-8.

50 W. Xu, J. Ding, L. Li, C. Xiao, X. Zhuang and X. Chen, Chem. Commun., 2015, 51, 6812-6815.
51 Y. Sun, Y. Chen, L. Tian, Y. Yu, X. Kong, J. Zhao and H. Zhang, Nanotechnology, 2007, 18, 447.

52 Q. Tian, W. Yao, W. Wu, J. Liu, Z. Wu, L. Liu, Z. Dai and C. Jiang, ACS Sustainable Chem. Eng., 2017, 5, 10889-10899.

53 Z. Xu, M. Quintanilla, F. Vetrone, A. O. Govorov, M. Chaker and D. Ma, Adv. Funct. Mater., 2015, 25, 2950-2960.

54 R. Lv, D. Yang, P. Yang, J. Xu, F. He, S. Gai, C. Li, Y. Dai, G. Yang and J. Lin, Chem. Mater., 2016, 28, 4724-4734. 